\title{
The Social Impact of Accounting Processes on Benefit Claimants in the UK
}

\author{
Julia A. Smith ${ }^{1}$ (D) Elena Doolan ${ }^{1}$ \\ Published online: 6 February 2020 \\ (C) The Author(s) 2020
}

\begin{abstract}
The accounting processes of categorisation and classification are inherent in modern-day welfare systems, though little has been done to investigate the link these have to the social consequences for benefit claimants within these systems. This paper uses research from both primary and secondary sources to show how UK welfare reform has affected claimants and their inalienable human rights since its introduction in 2012. The data gathered for this work combine face-to-face interview data with press releases, and data and reports compiled and published both by the government and independent bodies. Face-to-face interviews were conducted with two illustrative participants, who were identified as being excellent examples of individuals with a close working knowledge of the welfare system. In addition to the primary data gathered, several sources of secondary data are used within the analysis to identify facts, figures and quotations from reliable government sources. Our analysis uncovers that the accounting processes inherent in the system have helped foster a culture of stigmatisation, food bank dependency and financial and emotional hardship for vulnerable welfare claimants in today's society.
\end{abstract}

Keywords Categorisation $\cdot$ Classification $\cdot$ Accountability $\cdot$ Welfare system

\section{Introduction}

In recent years, literature has examined accounting and its social consequences (see Walker 2008, 2010, Roberts 2009), with many recently published papers linking historical human disasters, such as the Holocaust and slavery, with the accounting processes that helped to facilitate them; though little research has been done to link accounting processes with ongoing regimes in modern-day society. The United Kingdom (UK) is increasingly facing problems such as increased use of food banks, benefit sanctions and increased conditionality for benefit claimants (cf. Adler 2018; Patrick 2011; Watts \& Fitzpatrick 2018). The latter, in particular, which has been defined as 'the principle that entitlement to benefits should be conditional on satisfying certain conditions, most commonly undertaking work-related activity such as job search' (Stanley \& Lohde

Julia A. Smith

julia.smith@strath.ac.uk

Elena Doolan

elena.doolan.2013@uni.strath.ac.uk

1 Department of Accounting \& Finance, University of Strathclyde, Stenhouse Wing, 199 Cathedral St, Glasgow G4 0QU, UK
2004, p.1), is in direct contravention of the general principles of the Convention on the Rights of Persons with Disabilities, the Universal Declaration of Human Rights (UDHR) and the European Convention on Human Rights, all of which prohibit discrimination of any kind (cf. Alston 2018; UN General Assembly 1948, 2007; Council of Europe 1950). For example, Article 28 of the Convention on the Rights of Persons with Disabilities states that parties should acknowledge 'the right of persons with disabilities to an adequate standard of living for themselves and their families ... [and] ... take appropriate steps to safeguard the realization of this right without discrimination on the basis of disability'. However, Alston (2018, p.5) questions the ability of cash-constrained public sector entities to effectively guarantee non-discrimination. Nonetheless, the processes of categorisation, classification and reduction of human beings to numbers in a system are all accounting techniques that are inherent within a welfare system. We discuss how these processes have come to fashion a society where benefit claimants are stigmatised and labelled, can find themselves in hardship due to increased conditionality (cf. Dwyer 2018), and find that their personal problems are discarded by a system which has turned into a mechanical human processing machine rather than a societal support system.

The Welfare Reform Act 2012, enacted under the Conservative-Liberal Democrat coalition (2010-2015), laid 
Table 1 Key benefits, conditions and sanctions

\begin{tabular}{|c|c|c|c|c|c|}
\hline Benefit & Government & Purposes & Replaced & Conditions & Sanctions \\
\hline $\begin{array}{l}\text { Employment and } \\
\text { support } \\
\text { allowance } \\
\text { (ESA) }\end{array}$ & Labour (2008) & Focus on 'work capability' & Incapacity Benefit & $\begin{array}{l}\text { Work capability } \\
\text { assessment; } \\
\text { Undertake } \\
\text { work-related ac- } \\
\text { tivities }\end{array}$ & $\begin{array}{l}\text { Payment reduced; } \\
\text { Sanction may continue for up } \\
\text { to } 4 \text { weeks }\end{array}$ \\
\hline $\begin{array}{l}\text { Universal credit } \\
\text { (UC) }\end{array}$ & $\begin{array}{l}\text { Conservative/Liberal } \\
\text { Democrat coalition } \\
\text { (2012) }\end{array}$ & $\begin{array}{l}\text { For people over } 18 \text { but under } \\
\text { State Pension age who are } \\
\text { on a low income or out of } \\
\text { work }\end{array}$ & $\begin{array}{l}\text { Child Tax Credit; } \\
\text { Housing Benefit; } \\
\text { Income Support; } \\
\text { income-based } \\
\text { Jobseeker's } \\
\text { Allowance (JSA); } \\
\text { income-related } \\
\text { Employment and } \\
\text { Support } \\
\text { Allowance (ESA); } \\
\text { Working Tax Credit }\end{array}$ & $\begin{array}{l}\text { On a low income or } \\
\text { out of work; } \\
\text { Age } 18 \text { or over } \\
\text { (some exceptions } \\
\text { if } 16 \text { to } 17 \text { ); } \\
\text { Under State Pension } \\
\text { age; Have } \\
£ 16,000 \text { or less in } \\
\text { savings; } \\
\text { Live in the UK }\end{array}$ & $\begin{array}{l}\text { Lowest: failing to attend } \\
\text { Work-Focused Interview; } \\
\text { Low: failing to attend a } \\
\text { training course; } \\
\text { Medium: failing to be } \\
\text { available to } \\
\text { for interview or to start work; } \\
\text { High: refusing offer of a job. } \\
\text { All benefits ceased for a } \\
\text { period of time, according to } \\
\text { importance of failure to } \\
\text { comply }\end{array}$ \\
\hline $\begin{array}{l}\text { Personal } \\
\text { Independence } \\
\text { Payment (PIP) }\end{array}$ & $\begin{array}{l}\text { Conservative/Liberal } \\
\text { Democrat coalition } \\
\text { (2012) }\end{array}$ & $\begin{array}{l}\text { Help towards costs arising } \\
\text { from having long-term } \\
\text { health condition or disability }\end{array}$ & $\begin{array}{l}\text { Disability Living } \\
\text { Allowance (DLA) }\end{array}$ & $\begin{array}{l}\text { Age over } 16 \text { up to } \\
\text { state retirement } \\
\text { age; } \\
\text { Explain how } \\
\text { Disability affects } \\
\text { you; } \\
\text { Assessment }\end{array}$ & $\mathrm{n} / \mathrm{a}$ \\
\hline
\end{tabular}

Note: Table based on information from Bauld et al. (2012) and http://www.gov.uk

out plans for a major overhaul of the UK benefits system. Under the belief that the previous welfare system was overly complicated and provided 'insufficient incentives to encourage people to move off of benefits and into paid work' (GOV.UK 2015), the Government introduced a series of reforms to tackle these issues. The aims of so doing were to simplify the administration processes of the system and make it fairer for claimants, and to reduce poverty and dependency.

One of the greatest changes was the introduction of Universal Credit (UC) (cf. Table 1), a single payment which brings together a range of working-age benefits. Previously, claimants applied for different benefits from different agencies when in and out of work. Under UC, Income Support, Employment and Support Allowance, Child Tax Credit, Working Tax Credit and Housing Benefit, to name but a few, are combined into one single monthly payment, usually paid into a bank account. This system was designed to replicate how people are paid when in work in an attempt to bridge the gap between benefit claiming and working. It was further projected by the Government that UC would reduce poverty and provide an overall, easier process for claimants (DWP 2010). Under UC, those applying for Job Seeker's Allowance (JSA) (as well as those not seeking work) must comply with tight conditionality requirements in order to receive their benefit payment every month. A network of 'personal advisors' monitor claimants' compliance with 'workrelated requirements', which the claimant must commit to under the new conditionality regime (CPAG 2015; Patrick 2011; Watts \& Fitzpatrick 2018). Failure to meet these requirements results in a referral for a benefit sanction, in which benefits can be stopped completely, for up to a maximum period of 3 years. Universal Credit is now in place throughout the majority of the UK, and is the benefit that most new claimants will receive for income related support.

On the other hand, the Personal Independence Payment (PIP), brought in to replace, for the majority, the Disability Living Allowance, is a non-means-tested benefit that provides for those who have additional care needs, due to an illness or disability. Income and capital are ignored, for the purposes of assessment, and the benefit consists of both a daily living and a mobility component. Claiming this benefit can affect entitlement to other means-tested benefits, so the decision on entitlement is not always clear-cut (cf. HCWPC 2018). ${ }^{1}$ In Scotland, which gained some independent control for the country's social security powers, and where governing bodies have been highly critical of PIP, the Scottish Parliament now

\footnotetext{
${ }^{1}$ Indeed, the right decision on an individual's entitlement is not always made and, as the Commons Select Committee found, 'for at least 290,000 claimants of PIP and ESA - $6 \%$ of all those assessed - the right decision on entitlement was not made first time. Those cases, set alongside other problems throughout the application and assessment process, fuel a lack of trust amongst claimants of both benefits. The consequences - human and financial — can be enormous' (cf. HCWPC 2018, point 12).
} 
has power to create its own benefit to replace PIP and is considering more humane ways of doing so (Manji 2018).

Recent reports that assessments for PIP will stop in Scotland in early 2021, with no alternative yet in place, have led to concerns that vulnerable individuals will be in a state of confusion about the benefits they need and/or to which they are entitled. ${ }^{2}$ In a ministerial statement to the Scottish Parliament, the Cabinet Secretary for Social Security and older people, Shirley-Anne Somerville MSP, stated (28 February 2019):

'What I hadn't anticipated during this work was the further delay to DWP's DLA to PIP migration, which means that people of working age will still be on two benefits at the point where we'd expect them to transform to a single form of Scottish assistance.'

Evidence suggests there have been delays in making decisions on PIP, and escalating costs, due to processing appeals and reassessments (cf. McKeever 2019a). Whilst Universal Credit was introduced with the stated intention of simplifying the system, the reality suggests that this has not happened. Instead, the impact of welfare reforms has been significant and negative throughout the UK, with numerous reports and evidence testifying to this being the case (cf. HCWPC 2018; McKeever 2019a, b).

\section{Social Effects of Accounting}

Walker (2008) explained that accounting has vast social consequences and that written accounts of individuals can consequently build up perceptions in others. Categorisation and classification involve a process of 'labelling' by an authoritative body, which can potentially result in a build-up of negative social stereotypes and might, in turn, influence any resources distributed to them (cf. Jenkins 2014). Walker (2008) noted that an important aspect of collecting information on an individual is how far and wide this information is communicated or becomes visible. Cahill (1998) concurred that information that is gathered and recorded is the raw material of 'person production'. Such information is considered to strip an individual of their existence as a tangible human being, depersonalising and denoting them as merely a number or figure; and thereby reducing their human rights (cf. Alston 2018; UN 1948, 2007; Council of Europe 1950; Saffer et al. 2018). As a person is labelled or categorised, and as this information travels up the chain of the hierarchy, the view of this

\footnotetext{
$\overline{2}$ See also Patrick and Simpson (2019) on how the Scottish system's consideration of dignity in social security considerations differs from the rest of the UK.
}

person is moved out of context; they are represented as a number, rather than appearing as a person.

The essence of categorisation is that it simplifies complex identities in order to aid the decision-making process. Butler (2005) explained that it is impossible to give full detail in an account of oneself. This was confirmed by Strathern (2000) who argued that categories pale into insignificance in comparison with the more personal and detailed knowledge that we have of ourselves. In any situation where human behaviour needs to be recorded and monitored, essential complex and unique aspects of human life are relegated to mere checklists; then a human being can be treated simply as a number on a page and not as a person with raw emotions and feelings. This contravenes their basic human right to be treated with dignity (UN 1948). The consequences of this can be catastrophic for the self and for society (cf. Saffer et al. 2018).

Roberts $(1991,2009)$ warned that an individual's perception of 'self' can be built up by incorporating the views of others. He argues that our awareness of our own being develops alongside others' perceptions of oneself, suggesting that how you view yourself can be an amalgamation of what others think of you. In terms of categorisation and classification under Government policies such as welfare, the way a person is labelled could impact upon their sense of self; thus, categorisation affects a person's goals, what they think they are capable of, and how they feel they fit into society.

Categorisation is, however, unavoidable. Government welfare policy must rely on accounting processes, in order to efficiently distribute welfare to claimants. This infers 'complex classificatory logics’, as discussed by Mohr (1998), who argued that citizens are constituted as discursive subjects. Feminist scholars have explained how gender categories such as 'widow' or 'mother' are symbolic and allow people to make assumptions based on these labels. This is a perfect example of how accounting processes, though often viewed as impartial, actually have social consequences that are often left unexplored. Walker (2008) acknowledged this and was particularly critical of the way in which accounting 'labels' others. He argued that labelling people due to difference only adds to the stigma of the labelled; once a person has been tarred with a brush by society, it is hard for them to break out of this given identity (cf. Briant et al. 2013; Garthwaite, 2011; Garthwaite et al. 2013; Grover \& Piggott, 2013; McEnhill \& Byrne 2014).

Rhodes and Sagor (1976) put forward the notion that classification systems are a form of 'social and psychic control' for the dominant cultures, i.e. those at the top of the hierarchy. It has often been argued that labels tend to reflect the objectives that those in power wish to achieve (cf. Walker 2008). The further information travels up a chain of hierarchy, the more the descriptive information is eroded, until a person becomes a summary of statistics and achievements. Management decisions are based on budgets and 
figures which they take at fair value, divorced from the 'messy context in which they were produced' (Roberts 2009 p. 964). Funnel (1998) recognised how the use of accounting at the top of the hierarchy could be detached from its consequences at the bottom; he suggested that accounting has been able to hide under a blanket of anonymity and neutrality, largely because of its specialised and complex numerical process.

Walker (2010) showed how accounting for people is inherent in the discipline and punishment of human beings. The continuous hierarchical surveillance of facts and figures and of human accounts permits an effective strategy of authoritative praise and/or punishment, i.e. accountancy processes allow for the top of the hierarchy to control subordinates. Accounting is used to target populations, e.g. the surveillance of school pupils uses qualitative and quantitative data, thus rendering each individual 'calculable and manageable' (cf. Rose 1988). This system of human accounting was used to make visible children who were found to be different, whether through poor grades, cognitive delays, or truancy. Such a system, in monitoring children, has the potential to build up an indefinite stigma and label, which could impact that child's self-perception and place in society (cf. Roberts 2009; Saffer et al. 2018). Walker (2010) argued that this was like turning schools into factories, where there was a 'loss of humanism'. Funnel's (1998) paper developed the idea of power and discipline in accounting with a different slant, describing how accounting can be used as a means of disguise, in that reducing human beings to a set of ticked boxes and numbers can 'purify' immoral decision. These papers carry a similar message; accounting has social implications, which should not be overlooked simply because of the populist idea that accountancy is a set of numerical processes.

Foucault (1991) referred frequently to techniques that are used in accounting, including concepts such as hierarchy, accountability, classification and categorisation. He discussed how the means of social control moved from physical punishment to a discipline of personality and character (cf. Hoskin \& Macve 1986). This shift, in turn, introduced a new principle of individual accountability that establishes a numerical objective judgement on a person, and hence creates the idea of the 'calculable man' (Foucault 1991). Walker (2008) used a Foucauldian framework to show how documentation of individuals can have implications for identity, explaining that placing people in a field of monitoring and surveillance places them in a sea of documents and character summaries that are used to capture the essence of a person in a written format (cf. Foucault 1991). This kind of accounting for human beings is readily witnessed in the UK welfare system where, when registering for a particular benefit, an individual is monitored and their details and personal information recorded; hence, they are kept under a system of surveillance, where individuals are controlled and dominated.
Rose (1988) argued that Foucauldian disciplines of individualising human beings (such as calibrating their capacities and recording their attributes) 'makes' individuals by means of some rather simple technical procedures. Here it is suggested that accounting for human beings, by means of these categorisation and classification techniques, can start to shape the reality of who is an individual. Others have argued this can even start to shape perception of 'self' (e.g. Roberts 1991). Goslin and Bordier (1969) earlier suggested that recordkeeping of humans could impact behaviour, motivating and adding to perceptions of self. Roberts (1991) contended that, although the age-long perception of accounting is that it is an unbiased set of processes and techniques used to portray an objective picture, it is in fact subjective in what it reports.

Foucault (1991) explained that a mechanism of observation is integral within a disciplinary society. Roberts (1991) showed how, as an account of an individual travels up this hierarchical chain it becomes impersonalised and may be used by a distant group (e.g. managers) who are unidentifiable. This is the danger of accounting for human beings; it is a process of dehumanisation, where disciplinary decisions are made by a disassociated figure of authority. Walker (2010) drew upon Foucault's concept of the school describing it as a 'human observatory', a place for hierarchical powers to monitor and judge children, whilst analysing their achievements and behaviour.

\section{Accounting for Human Beings}

Accounting was an essential element of the 1834 Poor Law, a major government initiative with the aim of reducing levels of poverty in the UK. Records of an individual were recorded before a citizen was admitted to the workhouse; as a consequence, the Poor Law has been 'accorded a central place in the stigmatisation of poverty' (Walker 2008 p. 468). Individuals were categorised and made visible at the time as 'paupers'. The government intentionally used this process of classifying people in order to achieve their goal of embarrassing the poor back into work.

We can draw direct similarities with Funnel's (1998) discussion of how accounting was used in the Holocaust, to disguise or hide human lives behind a series of numbers and calculations, before the 'final solution' of extermination by gas chamber. Hitler employed similar techniques to those referred to in Walker's paper: categorising Jewish people to make them visible, recording their incomings and outgoings; and building up information profiles on each individual in order to track their activities. Accounting processes were used here to stigmatise Jews in society, who quickly became an underclass: degraded, humiliated and de-humanised (cf. Funnel 1998). Similarly, systems of Government welfare now herd their claimants through an administrative process, 
which has been streamlined to reduce costs and filter data on people as quickly as possible. Funnel (1998) gave an excellent assessment of how reducing human qualities to numbers on pages can have far-reaching, abhorrent consequences; those in power at the time believed that numbers were easier to work with than were human lives (cf. Rosenberg 1983).

This commodification of human beings is also explored by research into similar processes used in slavery in the USA. Just as the Jew was no longer valued as a human being, accounting worked to reinforce the racially-based social relationships in slavery by converting exchanges, holdings and outputs of people into monetary terms. Fleischman and Tyson (2004) point out that accounting is often detached from research on oppressive regimes such as slavery, as it is seen to provide a set of unbiased, neutral and moral-free procedures'. Oldroyd et al. (2008, p. 771) expanded on this idea, saying that 'the myth that slaves were less than human is one which agents and bookkeepers helped to perpetuate through commonly classifying them with the mules and cattle in inventories and valuations as livestock'. Although the socio-political context may have changed, accounting techniques still have the potential to produce similar outcomes.

The process of classifying and categorising people can have long-lasting effects. The main problem of stigmatisation is that, once branded in a certain way, the definition is hard to escape. Accounting practices such as categorisation can generate a specific self-perception for people; the categorisation of people in the UK welfare benefit system has the potential to leave individuals feeling stigmatised, de-motivated and pigeonholed (cf. Briant et al. 2013; Garthwaite et al. 2013; McEnhill \& Byrne 2014). Accepting relief in the 1800s, after the introduction of the Poor Law, was seen as becoming socially damned; this is not dissimilar to the consequences of applying for benefits today.

\section{Methodology}

Our ontological stance is that reality arises from both social construction and symbolic discourse (cf. Morgan and Smircich 1980). The belief that the reality of society morphs into whatever individuals interpret it to be reflects clearly the reality of the UK welfare system. How the needy are categorised by society is something that has been socially constructed in order to facilitate political processes and agenda. Since the birth of the Welfare State, multiple governments with different policy agendas have altered and reformed parts of the system in order to suit their political goals. Society itself, and those directly involved in the welfare system (e.g. government employees and claimants), must simply adapt to these changes; thus, the social reality for these individuals is forever shifting as the benefit system changes under new governments. Morgan and Smircich (1980) acknowledge that, under this ontological assumption, it is believed that society defines reality through different media, such as labels and actions, which are symbolic: the labels and categories to which human beings are currently subject are socially constructed by UK government policymakers. However, one difficulty of this, for example, since the introduction of Incapacity Benefit in 1995, and the Employment and Support Allowance (ESA), under the Labour Government of 2008 , is that many people who should have been declared 'unfit for work' were denied the benefits to which they were entitled. ${ }^{3}$ These classification changes have therefore affected what society believes to be reality.

The data gathered for this work combine face-to-face interview data with press releases, and data and reports compiled and published both by the government and independent bodies. Qualitative interviews were undertaken to gather first-hand information about personal, subjective experiences of the welfare system, as it was undergoing reform, providing an opportunity for us to learn about social life vicariously (cf. Boeije 2010). Specifically, face-to-face interviews were conducted with two illustrative participants, who were identified as being excellent examples of individuals with a close working knowledge of the welfare system: a 'Welfare Benefits Adviser' (interviewee A) and a 'Welfare Reform Change Programme Leader' of a large social housing group (interviewee B), in Scotland. ${ }^{4}$ The broad agenda (cf. Table 2) was pre-defined with an opportunity for follow-on questions to prompt a more in-depth, thorough answer, and approved by the University Ethics Committee prior to administration. It started with a brief overview of the interviewee's work role and experience. This was followed by a discussion of the impact of UK welfare benefit changes on both the job they undertook, and on the claimants they supported. Interviewee A's job was 'to maximise tenants' income in order to help them pay their rent'. Interview B, in her role of welfare reform as it relates to social housing, was tasked with 'developing a range of financial inclusion products for our customers ... ensuring that our staff and customers are aware of the changes that are happening ... ensuring that our policies, products, services are fit for purpose as the environment changes'. Thus, the discussion centred around the benefits with which they were familiar, and was led by their experience. It covered the process of claiming through the benefits system, and interpretation of the categorisation of disabilities, in particular. The contentious use of independent medical

\footnotetext{
${ }^{3}$ According to Griffiths (2011, p. 7) 'Close analysis of tribunal data and other source material since the introduction of Incapacity Benefit in 1995 suggests, at a very conservative estimate, that half a million people have been wrongly disallowed Incapacity Benefit, or, more recently, ESA. More than 300,000 have had their benefit restored at appeal after disallowance - at great public expense and personal and health cost.'

${ }^{4}$ As illustrative examples, these interviews were intended merely to support and/or refute the evidence from existing literature, and to provide insight into the real-life experience of the benefits system.
} 
Table 2 Interview agenda

1. Brief overview of interviewee's job role

2. Impact of UK welfare benefit changes on:

a. Job

b. Claimants

3. Detail of benefit system

a. Process of claiming

4. How disabilities are categorised

5. Use of independent medical reports

6. Changes in the administrative process

7. Incentivising people into work

8. Classification changes

9. Stigmatisation

reports (cf. Alston 2018) was discussed, along with changes brought into the administrative process. Respondents were asked whether the changes had had the desired effect of incentivising people into work. Finally, a discussion was had about the impact of changes to claimants' categorisation, and whether stigmatisation caused them not to seek benefit support (cf. Saffer et al. 2018).

In addition to the primary data gathered, several sources of secondary data were used within the analysis. In selecting these sources, we employed Scott's (1990) four criteria for analysing the authenticity, credibility, representativeness and meaning behind secondary sources (cf. Bryman 2012). Analysing the qualitative nature of this data involves searching for themes within the different sources (cf. Bryman 2012, p. 552). Using data gathered from news articles can be controversial, due to the political affiliations newspapers may have and the subjective nature of their analysis, particularly on government issues such as the ones analysed here. Bryman points out that there are 'conventional distinctions between tabloids and broadsheets', and hence, these should be approached with caution (2012, p. 553). Using Scott's criteria, there was a potential issue of authenticity and/or credibility concerning some press releases. Therefore, we have been cautious in selecting reports, mainly from broadsheet newspapers, that stick closely to reporting facts, figures and often directly report quotations from reliable government sources.

Overall, using newspaper and mass media articles was an appropriate research method for this paper. Due to the current, topical content of this paper, press releases and news articles have provided up-to-date coverage specifically concerning the issues discussed; there is plethora of press releases specifically concerning the social consequences of welfare reform in which accounting processes play a huge underlying role. In general, news articles and press releases are readily available and tend to provide clear and comprehensive evidence.

Additionally, evidence gathered from official government documentation is employed in this paper. Given that the welfare state and its related policies are in the hand of the government, it is essential that data and information be lifted from related documents. Bryman (2012, p. 550) notes that such materials 'can be seen as authentic and having meaning (in the sense of being clear and comprehensible to the researcher). Although there are issues with bias regarding these documents, the majority of the data used here are about the factual accounting processes of the system and how the rules and regulations of specific aspects of welfare reform operate. Official reports from both the government and private sources provide extensive textual analysis but do raise questions under Scott's four criteria concerning authenticity; therefore, we acknowledge the potential difficulties, and proceed with caution.

\section{The Process of Categorisation}

Increasing the conditionality of many welfare benefits is becoming popular social policy in many countries (Bauld et al. 2012). This means that, in order to claim benefits, the administration process is stricter, with people having to give detailed personal accounts and provide testimony of their condition to independent third parties, in order to prove their eligibility. Whilst the privatisation of this process might be seen as an effective and efficient way of managing resources, it can lead to the elimination of human rights protections and increase the marginalisation of those in society who are already vulnerable. As Alston (2018, p. 2) notes, 'existing human rights accountability mechanisms are clearly inadequate for dealing with the challenges presented by large-scale and widespread privatization [and] human rights proponents need to fundamentally reconsider their approach'. There are growing questions over whether the UK welfare system is protecting its most vulnerable claimants (cf. Patrick 2011). Under new requirements, people with disabilities have to provide detailed evidence of their incapacity in order to receive vital funds from the government. This has been criticised as a way of humiliating and terrorising those in society who have disabilities (cf. Penny 2010).

Our interviewee A explained her understanding of some of the changes to personal benefits, which had previously been assessed on what she perceived to be a 'reasonably qualitative' basis, ${ }^{5}$ as follows:

'People used to be on incapacity benefit, which was the sickness benefit that came in during Margaret Thatcher's time, but what happened was [there were] a lot of people who'd been working in industries like

\footnotetext{
${ }^{5}$ Note that the respondent believed the previous regime to be more qualitative, with greater opportunity for interpretation, than the current system. However, as the earlier system was points-based, her belief in its flexibility may be somewhat unsound. Further, her reference to the introduction of Incapacity benefit during 'Margaret Thatcher's time' is inaccurate, as the benefit was actually introduced during her successor, John Major's, time in office.
} 
mining and the steel works, and they were all closing down anyway, so quite a lot of people had gone on to sickness benefit at that point ... There wasn't really much of a reassessment; nobody really went back to them. They went on to incapacity benefit and then they sat on it for 20 years and then they got onto their state pension.

So ESA brought in a more stringent set of criteria to get the benefit, and what happened was [that] even if you were on a sickness benefit you would be moving towards employment, so they put people into one of two groups: the work-related group, which were people who they accepted they were not fit for work at this stage but may be in the future; and the support group, for people they accepted were not even fit for work related activity; so they were not fit for training, they were not fit for $\mathrm{CV}$ building classes.'

Moving on to changes in the ways in which disabilities are assessed, in order to get the new Personal Independence Payment, rather than the former Disability Living Allowance, the detail is condensed into a short checklist, as she explained: 'The criteria's changed... now it's a points scale they measure it by. So for every answer you give, you get a set of points and you need to score at least 8 points to pass'. This is a succinct description of how unique disabilities are being quantified and categorised under new legislation; instead of providing a qualitative, detailed description of how a person's illness/disability affects them, their condition is summarised on paper in order to gain 'points' for their incapacity to carry out tasks: 'on a housing benefit form ... it's just a tick box to say they've got a disability' (interviewee A). The processes are of the same nature as those discussed by Walker (2008), where a person is treated merely as a tally of attributes. Foucault (1991, p. 184) describes the concept of examining a subject as a way of qualifying and classifying that subject. Here, the application process a claimant goes through works in the same way, making the individual visible and comparable with others and subjecting them to a higher power who will judge them based on the account they give of themselves.

Foucault (1991, p. 189) suggested that the examination engages a person in a 'mass of documents that capture and fix them'. Within this categorisation process that people with disabilities must endure, their incapacities are examined closely and documented before a decision is made. One problem with this system was the failing of the examination to identify key aspects of those people's needs. An independent survey (cf. Bauld et al. 2012) noted that interviewees said their experience of these capability tests was that they had not been conducted in an appropriate manner, or by the relevant expert. As Alston (2018, p. 5) cautioned, 'what meaningful role can participation and accountability play when private corporations, operating on commercial principles, are taking key decisions affecting public welfare and individual rights?' It is clear that there are pitfalls in this examination process of classifying vulnerable groups; not instigating a clear, qualitative system can have significant social consequences.

\section{Re-categorisation as a Consequence of Reform}

This reformed process of classifying people with disabilities means that many claimants have become completely recategorised. Bauld et al. (2012) acknowledge that many problem drug users (PDUs), who once qualified for disability payments, due to addiction affecting mental health, are now being classed as job seekers. Whilst public health researchers tend to perceive problem drug use as an illness, public policy rarely supports this definition. Interviewee A explained how some claimants had now been re-classified, following the recent reforms:

'What happens now is that they're assessed on a much more regular basis if they're on a sickness benefit. And even if they're on a sickness benefit they're asked to go into the job centre to take part in maybe computer classes or adult literacy/numeracy classes; CV building; they're sent out to training centres. Which never, ever happened under incapacity benefit. And the problem we're finding is, for some people that's great, it's helping to build people's confidence, it's helping them to move back towards employment; but for other people, it's just not realistic.'

It is evident that claimants are almost powerless under the Government's regime; as the hierarchical power changes and tightens the classification procedure; those who use the system must yield and adhere to new rules. For groups such as PDUs, the reality of their situation and their status in society is completely re-configured due to government policy. As Interviewee A implied, 'the guys that wrote the guidelines [on welfare reform] ... obviously hadn't engaged much with the people that were going to be affected by it'. This assertion fits in well with Foucault's (1991) theory that a hierarchical power has 'eyes that must see without being seen'. Although the hierarchical power, in this case the DWP and Government, makes the rules of the welfare system, they are so far detached from the system they are unaware of its intricacies and failings.

A review of PIP by a collective group of charities for people with disabilities (the Disability Benefits Consortium, henceforth DBC) carried out in 2014 collected evidence from claimants on how they viewed the claiming process of this 
new benefit. Only just over a quarter (26\%) of those surveyed said that they were able to explain fully the impact of their condition on all aspects of their life through the claim form (DBC 2014). The report included direct quotes from conducted interviews where claimants described how the categorisation process failed to notice certain aspects of their disability:

'Our injury is due to cognitive impairment due to traumatic brain injury and we found it difficult to relate how this condition is affecting our daily living through questions asked on the claim form' (DBC 2014 p. 8).

This is a perfect example of how a stunted system of ticked boxes and categories on a form means that real human problems can be overlooked and remain ignored. It further amplifies how difficult and unpredictable the benefits system can be (cf. Saffer et al. 2018). One respondent in the DBC (2014) report, for example, described the full process as 'so black and white' that there was no room for qualitative elaboration or leeway for unique personal problems resulting from disabilities. Another interviewee from the same study backed up this assertion: 'what we said was twisted - even "by the time I have got washed and dressed I am totally exhausted' turned into 'can wash and dress herself!' (DBC 2014, p. 13). It is evident here that the categories provided on a form leave no room for qualitative discussion; accounting for people's needs via a sparse series of new categories is shifting them from one level of need to another. Thus efforts to standardise the wide range of potential disabilities is a failing function of welfare reform.

A PIP claim form is filled out by every potential claimant; the section on 'Managing toilet needs' asks a claimant to summarise their 'ability to go to the toilet and manage incontinence' (DWP 2014). The form requires the claimant to disclose whether they need to use aids in managing their toilet needs, including: 'bottom wipers, bidets, incontinence pads or collective devices such as bottles, buckets or catheters'. It further asks whether the claimant requires physical assistance in doing so. A claimant answers these questions simply by ticking a 'Yes/No/Sometimes' box, with little room for elaboration. This shows how degrading it can be to classify one's own incapacity to carry out everyday tasks (Briant et al. 2013; Garthwaite, 2011; Garthwaite et al. 2013; Grover \& Piggott, 2013; McEnhill \& Byrne 2014). The DBC's research into the success of PIP recognised that $69 \%$ of those they surveyed found filling out the claim form to be a difficult task. It is evident that there are many PIP claimants that cannot make themselves fully visible through the form as the categories are general with little room for claimants to discuss the real problems their condition causes them. The failings of the claim form to account for personal human needs has meant that many have failed to prove eligibility for the benefit. In addition to these fundamental faults, Turn2us' (2012) report acknowledges that many disability claimants found this process to be both humiliating and discouraging.

\section{Social Consequences of Categorisation and Classification}

The categorisation process of welfare reform has left many unaccounted for, and has changed the benefit status of many others. When a person becomes a summary of their physical or mental needs, certain personal aspects may be disregarded and hence some remain unrecognised within the appropriate categories (Walker 2008). There are real consequences for this in today's society. Funnel (1998) discusses how accounting, for many years has hidden behind a guard of neutrality. However, it is now being acknowledged that accounting processes are actually tools that can be used to achieve political agenda and, in the case of welfare reform, are facilitating the operation of a system that fails to account for vulnerable people. The system of claiming for PIP involves a summary of ticked boxes, but the system of classifying claimants is discriminating against vulnerable people because they cannot make themselves entirely visible through a simplified, abridged sea of categories (UN 1948, 2007; Council of Europe 1950).

Our respondent, interviewee A, spoke of the consequences that some people faced in seeking Employment and Support Allowance (ESA) when they no longer fell into a 'disabled' category. The advisor spoke of a tenant she dealt with who was on daily dispensed methadone but was reclassified as a jobseeker:

'He can't read or write and he's on 145mg of daily dispense methadone and they've been sending him to a [daily] computer class... he couldn't concentrate at all in the computer class ... because he needed the methadone. And then after he gets the methadone he can't function because it chills him out ... so obviously, he's failing to jump through that hoop'.

Here we see what kind of personal and social consequences this 'neutral' accounting technique has instigated. The personal experience of this claimant is evidence that the system fails to recognise people who have mental and physical difficulties that render it difficult for them comply with the demands of the job-seeking category. The requirements a job seeker must meet include attending courses, meetings and intense active job seeking. The applicant described above was not in a fit mental state to comply and was sanctioned as a result. The interviewee described it as 'demoralising' that a person like this cannot identify himself or herself within a new system that used to account for them. Because of this discriminatory 
categorisation, contrary to the UDHR (1948), which prohibits discrimination, and other relevant conventions, and his incapability to comply with new requirements, he has fallen into hardship. Having money cut off due to this failing means that many are struggling to feed themselves and heat their homes; the claimant above appears to be just one of many that have fallen into financial strain due to being placed in the welfare category.

Drug users are not the only claimants who have been harshly re-categorised under the new system; many people with unique physical/mental needs have not been appropriately accounted for and have had their claimant status changed dramatically under the reformed benefit system. A significant problem uncovered by research has been the failing of the specified categories to identify essential issues, specific or unique to a claimant. The DBC (2014) survey reported many examples of this; an issue that seems to recur commonly is summarised by one claimant:

'I will need some crutches to walk with soon. I am not able to make it round our supermarket anymore, yet I was turned down for mobility ... being turned down means I will have to continue to struggle which is going to have a detrimental impact on my mobility and therefore my ability to work' (DBC 2014 p. 19).

The specific issue raised here is the failure of the system to recognise people with slightly less severe mobility issues. Although the claimant may have been able to walk a few metres unaided, as specified in the PIP claim form, she was clearly struggling to carry out tasks that are key to maintaining a normal, healthy lifestyle. It is the purpose and responsibility of the welfare system to aid those in society who need extra support in living a normal life. The re-categorisation of people who used to qualify for disability benefits has meant many have been stripped of mobility cars and essential support money. Another respondent, who had failed to fit into new PIP categories, suggested worryingly that 'suicide was very appealing' (DBC 2014 p. 19). Re-categorisation is not just a 'neutral' accounting technique if the consequences in society include the deterioration of claimants' mental and physical states.

The accounting processes that underlie the policy of welfare reform are facilitating a system that makes vulnerable people invisible in society, causing them to struggle to live their daily lives. Chwe Onwurah, Member of Parliment (MP) for Newcastle upon Tyne, spoke passionately on these failings about a benefit claimant who had been receiving a disability benefit (ESA) for years before undergoing a work capability assessment in 2013 and was found 'fit to work'. After failed attempts to have this decision overturned, the claimant's mental health deteriorated rapidly and he consequently took his own life (House of Commons Debate 2015). The same debate had inputs from MPs from all across the UK, all of whom had similar stories from their constituencies and spoke of failings in the system to recognise those in need.

The social consequences resulting from this large scale recategorisation of needy people are widespread. The constituent who committed suicide is just one of many. UK newspapers have begun to commonly report on deaths and suicides deemed to be a direct result of welfare reforms, with the DWP investigating 60 claimant suicides in January 2015 (Cowburn 2015). Essentially, a common problem with classifying people is that the categories provided are too rigid; the constituent who committed suicide suffered from mental health problems that were not recognisable in the categories provided for disability benefit eligibility. Our interviewee A expressed concerns over how the re-classification of many of the vulnerable people she works with had badly affected their mental health. What is evident from our findings is that simple processes such as categorising benefit claimants, although seeming an innocent and mundane accounting process, are having a major impact in society. It appears that Government is branding and moving humans about from one status to another without much consideration of the consequences (cf. Oldroyd et al. 2008).

\section{Labelling and stigmatisation}

Being unfairly re-categorised under increased benefit conditionality is not the only aspect that causes detrimental social consequences. Those who remain in the welfare system are labelled by that very system. Jenkins (2014) discussed how classifying people involves a process of labelling, whereby possible negative stereotypes may be attached to individuals. Although Walker (2008) applied this to the labelling and stigmatisation in the Poor Law, we consider this idea in the context of welfare reform. As a claimant fills out a form, e.g. for the PIP benefit discussed above, they must state their circumstances. A claimant will tick boxes such as 'single ', 'parent' and 'carer' and hence, to the hierarchical decision-making power, that person will become a summary of labels assumed from their benefit form. Being labelled as a benefit claimant in modern day Britain can result in stigmatisation for those claimants (cf. Briant et al. 2013; Garthwaite et al. 2013; McEnhill \& Byrne 2014; Turn2us 2012). Hacking (1990) highlighted that categorisation defines a norm and hence facilitates the identification and treatment of abnormality in society; when people are categorised as a claimant, and then as a claimant of a specific benefit, they are made visible and classed as someone in need. The classification of that person can induce humiliation for a claimant, as they are distinguished as being different from societal norms. Walker (2008) argued that the accounting techniques of information processing and classification can lead to a 'spoiled identity'. 
For many benefit claimants, since the reform of 2012, this has become a reality. The Turn2us report (2012) on benefit stigma in Britain reports that this issue is widespread, with more than half of those surveyed reporting a moderate-to-high level of social and institution stigma carried from claiming benefits. The report highlighted that the status of 'benefit claimant' carries many negative social stereotypes. It recognised that this is mainly due to negative media coverage over the last couple of decades (Briant et al. 2013; McEnhill \& Byrne 2014). The reality of this stigmatisation due to social labelling is that many of those entitled to support from the government are being deterred from claiming due to the fear of being tarred with this brush. The Turn2us report found that one in four respondents to a 2012 Ipsos MORI survey gave at least one stigma-related reason for delaying for not claiming. We asked interviewee A to elaborate on this, and she agreed that there is a stigma involved and that many people who are entitled are worried about being labelled as a claimant:

'I was out at a woman yesterday who's 65 and she has got various illnesses and isn't fit for work any more; but she was adamant that she wouldn't claim for housing benefit because she didn't want the stigma of claiming benefits. And I think that's partly because of what you read in the press, and it's partly because of the bad reputation that benefit claimants get ... it's a stigma ... they don't want to be seen to be a claimant.'

Although this individual was clearly beyond the age at which she would be required to work, and therefore not subject to work-seeking conditionality because of this, and suffering from a number of ailments, she was still affected by the overall stigma associated with being a benefits claimant. Interviewee A acknowledged that the tenant she spoke of was just one of many people in her local area who were put off applying for money because being sorted into a category makes visible and differentiates people due to their needs, often making people feel exposed and ashamed of their status.

In the public eye, many benefit claimants are seen as less than human (cf. de Vries 2013). 'Infrahumanisation', the study of intergroup bias, is the use of research into human emotion to highlight how some groups in society are seen as 'outgroups'. People tend to identify benefit claimants with negative labels and characteristics such as 'lazy' and 'dishonest' (de Vries 2013). Furthermore, people have trouble imagining benefit claimants as experiencing complex human emotion such as 'awe', 'hope' and 'admiration', i.e. emotions that make a person uniquely human. The stigma of being categorised as a benefit claimant in modern day is so strong that it can lead to mild dehumanisation for those who claim. Turn2us' (2012) evidence supports this idea, suggesting that stigmatisation is forming a subclass in society where claimants are almost seen as second-class citizens (cf. Grover \&
Piggott 2010). One cause of this is because simply being on benefits can act as a marker for other characteristics that may be perceived negatively by the public. Chwastiak (1999) touched on this, arguing that the categories of benefits systems have socially constructed ideas of what claimants are like. He acknowledged that being pigeonholed as a 'single mother' has led to carrying the socially constructed idea that you are 'not working' and likened this to the creation of a 'brutish underclass'.

Foucault (1991) argued that 'examination' renders a subject visible within a network. When a person enters the benefit claiming process, they fill out personal forms and attend physical assessments before being categorised as a 'job seeker' or 'employment and support claimant'. They are subject to a similar examination process that, in the end, can make them feel exposed and labelled in the public eye. Foucault acknowledged that hierarchical powers look at the results of said examination, using them to differentiate and judge people; the consequences of this can create a social stigma or an extreme disproval of a personal or group in society. Many of the benefit claimants interviewed (cf. DBC 2014) conform to the framework presented by Foucault, mentioning feelings of humiliation or judgement from onlookers who view them to be of such low capability and stats because of the 'needy' categories under which they fall.

The stigmatisation and labelling that occur due to the use of basic accounting techniques of the benefit system are widespread and damaging, with many claimants carrying a visible social burden that many regard as 'shameful' (Turn2us 2012). Research has suggested that the stigma of claiming benefits in modern day Britain is so strong that several of those entitled to government support actually refuse to claim (cf. Briant et al. 2013; Garthwaite et al. 2013; McEnhill \& Byrne 2014). The negative stereotype held by the public in the UK has undermined the purpose of the entire system. A welfare system to help those who need support in society has turned into an embarrassing, last resort for people. The underlying techniques that facilitate the entire system (classification, categorisation, information processing) have made for a system which labels and shames vulnerable people, social consequences that accounting researchers are now starting to acknowledge.

\section{Impersonalisation of the Welfare System in Accounting for Its Claimants}

Funnell (1998) explained that powerful figures in the Nazi regime were able to simply gather humans together and move them to concentration camps, as well as to order their death, because these humans were reduced to a number on a page. Generations on, accounting for human beings within the UK welfare system also simplifies the classification of 
humans. Interview evidence points towards the increased use of benefit sanctions under welfare reform as being the main driver of this dehumanisation process: '[sanctions have] been done with no regard to the impact on specific individuals' [interviewee B].

Humans are not being treated as living, breathing people for whom a benefit sanction will have extreme consequences. Dr. David Webster of the University of Glasgow is a passionate advocate against the use of sanctioning within the welfare system, who claims that the DWP are 'sanctioning people willy nilly for not doing arbitrarily imposed things' (Butler 2015). As Funnel (1998 p. 437) suggested, it is a way for those in power to 'divorce themselves form the objectives and consequences of their work'. Our interviewee A had direct contact with many people who were judged to have been unfairly discriminated against, under the tighter regime:

'We had a lady who's got a prosthetic limb and she just had a new one fitted, and so she wasn't able to attend the job centre for a week, because she was obviously getting used to the new limb. And she was sanctioned for missing her sign-on date'.

The welfare reform system does not provide room for a person to provide an excuse for a claimant who misses an appointment, no matter how valid this is. Interviewee A spoke of another case:

'I had a man in his 50s the other day, crying in the booth because he's lost all his money and he's been unemployed; he's been on incapacity benefit for years and then failed the medical when they moved from incapacity to ESA, so now he's on Job Seekers' ... he's doing everything that they're asking him to do... they sanctioned his money cause they said he wasn't doing enough to look for work, and he's just totally demoralised, because what really can you do, with a 30-year gap in your CV?'

MP Chwe Onwurah argued that 'the employees of the Department and its agencies (public servants) have forgotten, or been told to forget, that benefit claimants are people: human beings with lives, loved ones and feelings' (House of Commons Debate 2015). The process of categorising people enters them into a mass of documentation (Foucault 1991) and the account of one human being is lost amongst this reservoir of evidence (cf. Power, 2004; Roberts 2009).

Interviewee A from our own fieldwork suggested that accounting for humans has become so impersonal that those working in the field are detached from the fact that the target they need to reach is achieved by ultimately causing families go hungry and fuel poverty. There are endless individual accounts of people personally affected by this de-humanising system, which support this view. For example, see the evidence presented by one of Moriarty's (2014) cases:

'My benefits were sanctioned for three months ... I had failed to apply for one specific (inappropriate) job handed to me by my advisor at the job centre. The fact that I had been for a job interview that week, had another lined up and applied for at least 10 others was ignored ... my mental health deteriorated rapidly ... hardship payments were not enough to live on, or pay rent and I was thoroughly destitute by the end of my benefit sanction.' (Moriarty 2014).

It is believed that many benefit sanctions have been 'used disproportionately and applied harshly and arbitrarily' (Adler 2018, p. 137), and that claimants are being treated inequitably, due to the disengagement of hierarchical decision-makers (cf. Alston 2018).

Moriarty's (2014) example just above eventually had his sanction overturned but, by this point, he had already suffered because of harsh punishment. Our own interviewee B acknowledged the detachment of the system, in terms of claimants attempting to have their sanctions overturned:

'They need to go to the DWP and request a form, that form is then sent into them. It's sent to Inverness, they make a decision and it goes back to the tenant'.

The person or 'decision-maker' who must decide whether a sanction was administered unfairly is someone disconnected from the personal circumstances of the sanctioned claimant. Again, they view the claimant as a summary of facts and figures on a piece of paper. The claimant has essentially been dehumanised in the eyes of a decision-maker. Many of the rules regarding sanctions seem to have been put in place to streamline an efficient welfare machine that pushed claimants through the system as quickly as possible, with the least complication. Unfortunately, we know from history it is not easy to herd human beings through a costing system without causing social problems. When we spoke to interviewee B she gave a notable example of the daily realities facing many in need:

'the DWP changed the rule so that kids are not allowed in the job centre anymore; so a woman turned up with her pram and her kid and she's told she can't bring that pram inside so [she missed one meeting and was sanctioned].'

Although making efficiencies like this in a business environment is the norm, it has proven inappropriate in a system that should be helping vulnerable people. Many people struggle to gather a bus fare to attend meetings, and finding money to cover childcare whilst attending the job centre is likely to be a 
significant issue. In using a 'one rule fits all' work place attitude, many vulnerable people are receiving harsh or unfair sanctions.

Evidence suggests that the UK welfare system has become a robotic, mechanical costing system, particularly since welfare reform. Those at the top of the hierarchy (DWP) have become somewhat detached from the claimants at the bottom of the hierarchy, by means of a system that has removed steps of personal contact. Decisions made to cut the costs of administration and produce a more efficient, cost-effective system have imposed strict conditionality on some benefits, to reduce fraud and sanction people who do not comply with the rules, in order to force them into work. Reducing humans down to numbers in a system can have dangerous consequences, such as an increase in food and fuel poverty, or a strong social stigma, as witnessed by many today.

\section{Conclusion}

The aim of this paper was to examine the accounting processes of categorisation, classification and hierarchical accountability in the context of accounting for human beings, and to explore whether the conventions of the United Nations $(1948,2007)$ and Council of Europe (1950) are being breached, in any measure. The accounting processes inherent in the current benefit system in the UK have facilitated many detrimental, and often devastating social consequences. Using Foucault's work as a reference point, the DWP has a hierarchical position of power, which allows it to enforce both direct and indirect forms on discipline on claimants at the bottom of the hierarchy. On entering the welfare system, claimants go through a subtle form of examination whereby their attributes, struggles and social status are summarised on forms and papers, which are then examined by 'invisible' administrators. These forms become a representation for that person within a system that processes millions of human beings in the UK.

This can create a detrimental social stigma for claimants; many are put off from claiming in the fear of being labelled needy, those who do claim carry a humiliating burden. There appears to be an inequality of treatment of the individual, given the inability of the current systems to identify those individuals. Research into the increased use of sanctions has unveiled that that welfare system has come to treat its claimants as numbers on paper, exploiting vulnerable people in order to make statistical targets. Many have been forced into severe poverty, depression, suicide and hunger, caused in part by the impersonalisation of the welfare system. Many government and non-government-related bodies have highlighted problems and made recommendations to those at the top of the hierarchy for change in these area. However, it appears problems such as stigmatisation and dehumanisation may remain ingrained in a system where vulnerable claimants are treated as statistics instead of real people.
We have drawn direct lines between accounting processes and the social consequences of accounting for human beings through an impersonalised, detached system in which a hierarchical power can act in a disciplinary fashion. The traditional view of accounting as a culmination of neutral processes and techniques is one that is being cast aside by many social and critical accounting researchers (e.g. Walker 2008; Funnel 1998; Oldroyd et al. 2008). Recent research has linked accounting processes to the facilitation of devastating historical regimes such as war and slavery, but few have linked these processes with devastating consequences happening currently.

Through analysis of the accounting processes of classification, categorisation, information systems and accountability, this paper has uncovered how human beings are accounted for as they enter the UK welfare system as a benefit claimant. Increased conditionality, particularly for claimants with disabilities, has meant that many people in need have been made invisible and unable to categorise themselves within the system, resulting in financial and mental hardship. Categorising people as 'needy' stigmatises welfare claimants, to the extent that many refuse to claim their entitlements, in order to avoid being labelled by society. Further analysis of the sanctioning system in the UK shows how the summarisation of welfare claimants has allowed them to be accounted for as numbers in a system, rather than as human beings with real issues. Accounting for people in this way creates a system of dehumanisation, and the detachment of those at the top of the hierarchy from those at the bottom creates a subset of vulnerable people struggling to pay their rent, feed themselves or heat their homes.

Acknowledgements The authors are grateful to participants in the fieldwork stages of this study for their kindly cooperation and input. Any errors of omission or commission remain the authors' own.

\section{Compliance with Ethical Standards}

Conflict of Interest The authors declare that they have no conflict of interest.

Ethical Approval All procedures performed in studies involving human participants were in accordance with the ethical standards of the institutional and/or national research committee and with the 1964 Helsinki declaration and its later amendments or comparable ethical standards.

Informed Consent Informed consent was obtained from all individual participants included in the study.

Open Access This article is licensed under a Creative Commons Attribution 4.0 International License, which permits use, sharing, adaptation, distribution and reproduction in any medium or format, as long as you give appropriate credit to the original author(s) and the source, provide a link to the Creative Commons licence, and indicate if changes were made. The images or other third party material in this article are included in the article's Creative Commons licence, unless indicated otherwise in a credit line to the material. If material is not included in the article's Creative Commons licence and your intended use is not permitted by 
statutory regulation or exceeds the permitted use, you will need to obtain permission directly from the copyright holder. To view a copy of this licence, visit http://creativecommons.org/licenses/by/4.0/.

\section{References}

Adler, M. (2018). Cruel, inhuman or degrading treatment. London: Palgrave Macmillan.

Alston, P. (2018). Report of the special rapporteur on extreme poverty and human rights. United Nations General Assembly.

Bauld, L., McKell, J., Carroll, C., Hay, G., \& Smith, K. (2012). Benefits and employment: how problem drug users experience welfare and routes into work. Journal of Social Policy, 41(4), 751-768.

Boeije, H. (2010). Analysis in qualitative research sage: USA.

Briant, E., Watson, N., \& Philo, G. (2013). Reporting disability in the age of austerity: The changing face of media representation of disability and disabled people in the United Kingson and the creation of new 'folk devils'. Disability \& Society, 28(6), 874-889.

Bryman, A. (2012). Social research methods 4th addition. New York: Oxford University Press.

Butler, J. (2005). Giving an account of oneself. Oxford University Press.

Butler, P. (2015). Benefit sanctions: they're absurd and don't work very well, experts tell MPs The Guardian. $8^{\text {th }}$ January [online] Available at: http://www.theguardian.com/society/patrick-butler-cuts-blog/ 2015/jan/08/benefit-sanctions-absurd-and-dont-work-mps-toldwelfare.

Cahill, S. (1998). Toward a sociology of the person. Sociological Theory, 16(2), 131-148.

Chwastiak, M. (1999). Deconstructing the principal-agent model: A view from the bottom. Critical Perspectives on Accounting, 10(4), 425441.

Council of Europe, European Convention for the Protection of Human Rights and Fundamental Freedoms, as amended by Protocols Nos. 11 and 14, 4 November 1950, ETS 5, available at: https://www. refworld.org/docid/3ae6b3b04.html [accessed 25 June 2019].

Cowburn, A. (2015). Suicides highlight the grim toll of benefit sanctions in austerity Britain The Guardian. $3^{\text {rd }}$ January [online] Available at: http://www.theguardian.com/society/2015/jan/03/benefitssanctions-leading-suicides-dwp-depression

CPAG. (2015). Universal Credit for tenants in social housing [Information pack provided by Glasgow Housing Association] Available for request [Online] at: http://www.cpag.org.uk/content/ universal-credit-tenants-social-housing-1

De Vries, R. (2013). Benefit claimants are now seen as other - Less than fully human The Guardian. 11 ${ }^{\text {th }}$ May [online] Available at: http:// www.theguardian.com/commentisfree/2013/may/11/benefitsclaimants-other-research.

Department for Work and Pensions (DWP). (2010). Universal Credit: welfare that works [online] Available at: https://www.gov.uk/ government/uploads/system/uploads/attachment_data/file/48897/ universal-credit-full-document.pdf.

Department for Work and Pensions (DWP). (2014). PIP Assessment Guide [online] Available at: https://www.gov.uk/government/ uploads/system/uploads/attachment_data/file/368122/pipassessment-guide.pdf.

Disability Benefits Consortium (DBC). (2014). Independent Review of Personal Independence Payment (PIP) Response from the Disability Benefits Consortium (DBC) [pdf] DBC Available at: https://www. rcpsych.ac.uk/pdf/DBC\%20PIP\%20independent\%20review\% 20submission\%20Sep\%202014.pdf.

Dwyer, P. (2018). Welfare conditionality project 2013-2018: Final findings report. York: University of York/JRF.
Fleischman, R., \& Tyson, T. (2004). Accounting in service to racism: Monetizing slave property in the antebellum South. Critical Perspectives on Accounting, 15(3), 376-399.

Foucault, M. (1991). Discipline and Punish: The Birth of the Prison (3rd ed.). London: Penguin.

Funnel, W. (1998). Accounting in the service of the holocaust. Critical Perspectives on Accounting, 9(4), 435-464.

Garthwaite, K. (2011). 'The language of shirkers and scroungers?' Talking about illness, disability and coalition welfare reform. Disability \& Society, 26(3), 369-372.

Garthwaite, K., Bambra, C., \& Warren, J. (2013). The unwilling and the unwell? Exploring stakeholders' perceptions of working with long term sickness benefits recipients. Disability \& Society, 28(8), 1104 1117.

Goslin, D. A., \& Bordier, N. (1969). Record-keeping in elementary and secondary schools. In S. Wheeler (Ed.), On record. Files and dossiers on American life (pp. 29-65). New York: Russel Sage Foundation.

GOV.UK. (2015). Policy: Simplifying the welfare system and making sure work pays [online] available at: https://www.gov.uk/government/ policies/simplifying-the-welfare-system-and-making-sure-workpays.

Griffiths, S. (2011). The misuse of evidence in incapacity benefit reform. Soundings, 47, 7-20. https://doi.org/10.3898/ 136266211795427503.

Grover, C., \& Piggott, L. (2010). From incapacity benefit to employment and support allowance: Social sorting, sickness and impairment and social security. Policy Studies, 31(2), 265-282.

Grover, C., \& Piggott, L. (2013). Disability and social (in) security: emotions, contradictions of 'inclusion'and Employment and Support Allowance. Social Policy and Society, 12(3), 369-380.

Hacking, I. (1990). The taming of chance. Cambridge: Cambridge University Press.

Hoskin, K. W., \& Macve, R. H. (1986). Accounting and the examination: A genealogy of disciplinary power. Accounting, Organizations and Society, 11(2), 105-136.

House of Commons Debate. (2015). Col112WH $7^{\text {th }}$ Janurary [Online] Available at: http://www.publications.parliament.uk/pa/cm201415/ cmhansrd/cm150107/halltext/150107h0001.htm\#15010768000001

House of Commons Work and Pensions Committee (HCWPC). (2018). PIP and ESA assessments: Seventh Report of Session 2017-19, HC829, 14 February, at https://publications.parliament.uk/pa/ cm201719/cmselect/cmworpen/829/82902.htm.

Jenkins, R. (2014). Social identity. London: Routledge.

Manji, K. (2018). 'It was clear from the start that [SDS] was about a cost cutting agenda.' Exploring disabled people's early experiences of the introduction of Self-Directed Support in Scotland. Disability \& Society, 33(9), 1391-1411.

McEnhill, L., \& Byrne, V. (2014). Beat the cheat: portrayals of disability benefit claimants in print media. Journal of Policy and Social Justice, 22(2), 99-110.

McKeever, G. (2019a). PIP. Journal of Social Security Law, 26(2), 57-58.

McKeever, G. (2019b). Impact of welfare reforms. Journal of Social Security Law, 26(2), 60-61.

Mohr, J. W. (1998). The classificatory logics of state welfare systems: Towards a formal analysis. Public Rights, Public Rules: Constituting Citizens in the World Polity and National Policy, pp. 207-238.

Morgan, G., \& Smircich, L. (1980). The case for qualitative research. Academy of Management Review, 5(4), 491-500.

Moriarty, S. (2014). Written evidence provided to a House of Commons Work and Pensions Select Committee. Available online: http://bit.ly/ luvfWr5.

Oldroyd, D., Fleischman, R., \& Tyson, T. (2008). The culpability of accounting practice in promoting slavery in the British Empire and antebellum United States. Critical Perspectives on Accounting, 19(5), 764-784. 
Patrick, R. (2011). Disabling or enabling: The extension of work-related conditionality to disabled people. Social Policy \& Security, 10(3), 309-320.

Patrick, R., \& Simpson, M. (2019). Conceptualising dignity in the context of social security: Bottom-up and top-down perspectives. Social Policy \& Administration. Early online: https://doi.org/10.1111/ spol.12528.

Penny, L. (2010) How the disabled were dehumanised: Laurie Penny on Jody McIntyre NewStatesman [online] $16^{\text {th }}$ December. Available at: http://www.newstatesman.com/blogs/laurie-penny/2010/12/realdisabled-jody-mcintyre

Power, M. (1994). 12 The audit society. Accounting as Social and Institutional Practice, 24, 299.

Rhodes, W. C., \& Sagor, M. (1976). Community perspectives. In N. Hobbs (Ed.), Issues in the classification of children volume one (pp. 101-129). Washington: Jossey-Bass.

Roberts. (1991). The possibilities of accountability. Accounting Organizations and Society, 16(4), 355-368.

Roberts, J. (2009). No one is perfect: The limits of transparency and an ethic for 'intelligent' accountability. Accounting, Organizations and Society, 34(8), 957-970.

Rose. (1988). Calculable minds and manageable individuals. History of the Human Sciences, 1(2), 179-200.

Rosenberg, A. (1983). The philosophical implications of the Holocaust. In Perspectives on the Holocaust (pp. 1-18). Springer Netherlands.

Saffer, J., Nolte, L., \& Dufy, S. (2018). Living on a knife edge: The responses of people with physical health conditions to changes in disability benefits. Disability \& Society, 33(1), 1555-1578.
Scott, J. (1990). A Matter of Record: Documentary Sources in Social Research. Cambridge, UK: Polity Press.

Stanley, K., \& Lohde, L. (2004). Sanctions and Sweeteners: rights and responsibilities in the benefits system. London: Institute for Public Policy Research.

Strathern, M. (2000). New accountabilities. Audit cultures: Anthropological studies in accountability, ethics and the academy, pp. $1-18$.

Turn2us. (2012). Benefits stigma in Britain [pdf] Turn2us. Available at: https://wwwturn2us-2938.cdn.hybridcloudspan.com/T2UWebsite/ media/Documents/Benefits-Stigma-in-Britain.pdf.

UN General Assembly, Universal Declaration of Human Rights, 10 December 1948, 217 A (III), available at: https://www.refworld. org/docid/3ae6b3712c.html [accessed 25 June 2019].

UN General Assembly, Convention on the rights of persons with disabilities: resolution/adopted by the General Assembly, 24 January 2007, A/RES/61/106, available at: https://www.refworld.org/docid/ 45f973632.html [accessed 25 June 2019].

Walker, S. (2008). Accounting, paper shadows and the stigmatised poor. Accounting, Organizations and Society, 33(4-5), 453-487.

Walker, S. (2010). Child accounting and 'the handling of human souls'. Accounting, Organizations and Society, 35(6), 628-657.

Watts, B., \& Fitzpatrick, S. (2018). Welfare conditionality. Abingdon: Routledge.

Publisher's Note Springer Nature remains neutral with regard to jurisdictional claims in published maps and institutional affiliations. 